\title{
A PRELIMINARY STUDY OF FACE-TO-FACE VERSUS ONLINE LEARNING
}

\author{
Marzie Astani, Ph.D. Winona State University, mastani@winona.edu \\ Chris Malone, Ph.D. Winona State University, cmalone@winona.edu
}

\begin{abstract}
The growth of online programs has instigated many higher educational institutions to consider are consider offering online courses and programs. Although many higher educational administrators recognize some benefits of online education, such as flexibility for students, they need to assess the value of online education for their own organizations before allocating resources. One of the concerns cited in the literature is the effectiveness of online education. Although several research studies have been done on the quality of online courses, more research is needed concerning the learning effectiveness of online courses. This study examines student's perceptions of online courses versus face-to-face concerning several quality indicators mentioned in the literature. The results of our study indicate that for all the examined quality indicators the online and face-to-face learning are the same from students' perspectives. Suggestions for higher education institutions considering the adoption of online courses/programs are provided.
\end{abstract}

Keywords: Online learning, Students’ perception, Quality indicators, Active involvement

\section{INTRODUCTION}

Many higher education institutions have been offering online courses/programs in response to increasing demand. The rapid growth of online learning has been documented in the literature. Pethokoukis [8] reported 33\% per year increase in online enrollment in the U.S. through 2002. In a study of 277 Business schools [1], nine percent of institutions reported at least one online program in 2001-2002. By 2008-09, 24\% of these schools offered online programs. Similarly, in a 2005 research study of education in the U.S, the growth rate for online enrollment was reported at $18.8 \%$, which exceeded the overall growth rate in the higher education student body [2]. The largest increase (72\%) was for associate degree institutions; sixty-five percent of schools were offering traditional graduate programs along with online courses, and sixty-three percent of traditional undergraduate programs offered online courses [2]. Overall, fifty-six percent of higher educational institutions identified online education as a critical longterm strategy. Higher education institutions are increasingly considering online course offerings as part of their strategic planning process in order to compete in the educational marketplace.

In spite of widespread growth and expanding online program offerings, there have been controversies regarding the quality of online education. Several studies have been conducted comparing online with traditional face-to-face learning concerning the design, effectiveness, and students' performance as indicators of course quality. For example, McFarland and Hamilton [7] examined the level of student engagement as an indicator of quality and found no difference in satisfaction or performance of students enrolled in online versus those students enrolled in traditional courses. In another study, Russel [11] focused on student exam performance and found that learning outcomes were comparable in both online and traditional teaching modes.

This study investigates students' perceptions of the two learning environments, online versus face-to-face learning, based on several quality learning indicators mentioned in the literature. It involves using College of Business students' evaluation survey data from a Midwestern university to examine the quality of learning. This research is more comprehensive since the comparison is based on several quality indicators. The objective is to determine whether there is a significant difference in the learning effectiveness of the two delivery modes from students' perceptions. Literature review and methodology will follow this introduction section. Finally, the results and conclusion/discussions will be presented. 
Volume XII, No. 2, pp 287-292, 2011

\section{LITERATURE REVIEW}

Several research studies have been conducted comparing the two delivery systems, online and face-to-face settings, and concluded that there is no significant difference in the learning outcomes of students in both systems (e.g., [20]). Other researchers reported that online students showed higher levels of engagement than those of traditional learners and students gained knowledge and acquired skills that facilitated their understanding of real-world and job-related problems [26]. Furthermore, some researchers propose that the online environment facilitates lifelong quality learning [2], which contributes to students' daily lives [7]. Moreover, Reynolds [25] found that the majority of students had to work harder to meet academic expectations in online courses. In their research study, Conrad and Donaldson [10] reported that online participants worked collaboratively with other students and demonstrated a high level of engagement in critical and analytical thinking. Technology employed in online environment is believed to enrich learning and creates meaningful experiences that contribute to the learner's growth and development [10]. Robinson and Hullinger [26] suggest that the learner's autonomy to learn on their own is a major advantage to online learning.

However, some researchers have raised concerns related to a potential compromise in quality and learning experience for online versus traditional face-to-face learning [e.g., 26]. Some studies have cited several disadvantages in online courses, including lack of interaction (student-to-instructor and/or student-to-student), privacy issues, technological difficulties, and a focus on technology rather than content (e.g., [5, 23]). The lack of students' engagement and isolation are issues in online learning since most of the online courses are asynchronous, allowing learners to participate from different locations, and thereby may result in learners' feeling of isolation. To address this issue, Kuh [16] recommends that students should be provided with opportunities to contribute to class discussion, work with other students, and engage in other class activities. Researchers conclude that the online environment should foster collaborative efforts to promote learning and create a learning community, which is very different from many traditional education programs $[4,6]$. Researchers recommend that collaborative activities need to be embedded in online learning to provide opportunities for learners to increase social presence, reduce feelings of isolation and gain a sense of online community. This process involves participants learning through interactions with their peers [11, 27]. Further, Hinltz \& Turoff [12] argue that learners' anxiety and uncertainty are reduced as learners communicate with their teammates to find solutions to complex problems or new tasks, instead of alone, or just with the instructor [31].

Many researchers conducted studies comparing online and face-to-face learning modes from learners' perspectives. For example, Klesius et al. [6] found that learners' satisfaction with online learning was the same as traditional faceto-face courses.

In another study, Ponzurick et al. [10] found that learners prefer the traditional face-to-face method of delivery over the online learning approach. However, more research studies are needed to understand the students' perceptions of online learning to help higher educational institutions better serve learners. This research investigates the possible difference between the two modes of delivery by using several quality indicators that have been identified in the literature from students' point of views.

\section{RESEARCH METHODOLOGY AND RESULTS}

The objective of this exploratory study is to investigate whether there is significant difference between the quality of online and face-to-face learning environments in students' perception and gain an insight about quality of education to help educational institutions better target their audience. To this end, we used the College of Business data from a Midwestern university. The survey was composed of 13 questions. We selected those survey items (a total of seven items) that were related to the quality indicators found in the literature, shown in Table 1. 
Volume XII, No. 2, pp 287-292, 2011

Table 1. Survey items related to quality indicators

\begin{tabular}{|rl|}
\hline & \multicolumn{1}{|c|}{ Survey Item } \\
\hline 1. & Learning Objectives were clearly communicated. \\
\hline 2. & Standards / expectations for class performance were clearly established. \\
\hline 3. & Feedback was frequent and timely. \\
\hline 4. & Collaboration among classmates was encouraged. \\
\hline 6. & Active involvement was required. \\
\hline 7. & Instructor was responsive to student concern. \\
\hline
\end{tabular}

Survey items were rated on a 5-point Likert Scale (5=strongly agree through $1=$ strongly disagree) by College of Business students. A total of 5480 students' responses to the survey were collected over three years. The number of observations for online courses was 233 versus 5247 face-to-face sample size. Figure 1 demonstrates the proportions of the two delivery systems. As shown, the number of online courses offered by the College of Business was too small compared to the face-to-face classes. Perhaps this fact may have some effects on the results of this research. Therefore, we need to be cautious in interpreting the results.

The Chi-Square test of Independence was used to analyze the data. The hypothesis was formed for each quality indicator as follows:

The pattern of survey responses are the same for online and face-to-face delivery modes.

Figure 1. Online and face-to-face observations (1= face-to-face, $2=$ online)

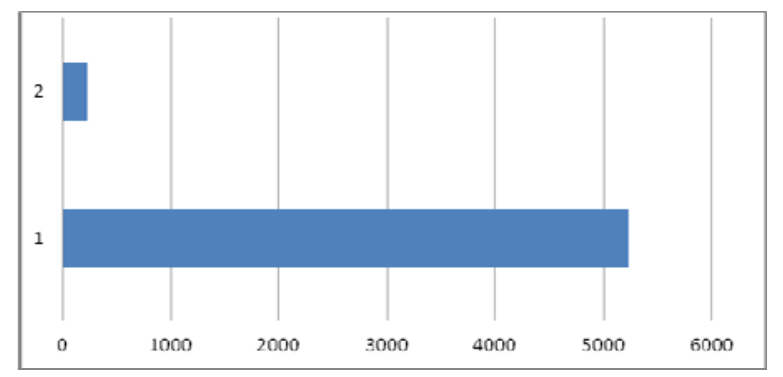

The results for all quality indicators are shown in Table 2. The table demonstrates the results of the statistical analysis for all seven quality indicators and the P-value of the survey items for the two learning modes, online and face-to-face.

As shown in Table 2, based on the P-Values, there is a strong significant difference for all quality indicators between online and face-to-face learning modes except for quality indicator number 5, "Active involvement was required." This means that students perceive the requirements for "Active involvement" are the same in the online and face-toface courses.

Table 2. Chi-Square test of Independence for online with face-to-face

\begin{tabular}{|l|c|}
\hline \multicolumn{1}{|c|}{ Survey Items } & P-Value \\
\hline 1.Learning objectives were clearly communicated. & .0001 \\
\hline 2.Standards / expectations for class performance were clearly established & .0001 \\
\hline 3.Feedback was frequent and timely. & .0001 \\
\hline 4.Collaboration among classmates was encouraged. & .0217 \\
\hline 5.Active involvement was required. & .3942 \\
\hline 6.Instructor was responsive to student concern. & .0001 \\
\hline 7.Instructor-student interaction was provided. & .0001 \\
\hline
\end{tabular}


Volume XII, No. 2, pp 287-292, 2011

The details of the results revealed more about the students' perception. Table 3 shows the percentage ratings for all quality indicators considered. As illustrated in Table 3, the same percentage of participants either strongly agreed/agreed with "Active involvement was required" for the course in both delivery systems. The percentage of students being uncertain about this quality item was 13 for face-to-face versus 10 for online. Only about thirteen percent of students strongly disagreed/disagreed with "Active involvement was required." Fifteen percent of students were uncertain about this statement in the face-to-face group versus eighteen percent in the online learning category. This is another indication of no significant difference in perception of students for "active involvement" for the two delivery modes.

As shown in Table 3, students' perceptions were different for all other quality indicators in face-to-face versus online learning. For example, higher percentages of students strongly agreed/agreed with item numbers 1 and 2, "Learning objectives were clearly communicated" and "Standards/expectations for class performance were clearly established." Overall, students seem to be leaning toward face-to-face courses as their favorite mode of delivery as oppose to online classes.

Table 3. Participants percentage ratings for face-to-face and online courses ( $1=$ strongly disagree through $5=$ strongly agree)

\begin{tabular}{|l|l|l|l|l|}
\hline \multicolumn{2}{|c|}{ Survey Item/ Delivery mode } & Disagree & Uncertain & Agree \\
\hline 1 & F2F & 9 & 11 & 80 \\
& Online & 13 & 15 & 71 \\
\hline 2 & F2F & 9 & 11 & 80 \\
& Online & 16 & 17 & 67 \\
\hline 3 & F2F & 13 & 14 & 73 \\
& Online & 26 & 17 & 58 \\
\hline 4 & F2F & 13 & 17 & 71 \\
& Online & 9 & 15 & 76 \\
\hline 5 & F2F & 13 & 15 & 72 \\
& Online & 10 & 18 & 72 \\
\hline 6 & F2F & 9 & 12 & 79 \\
& Online & 19 & 17 & 63 \\
\hline 7 & F2F & 8 & 12 & 79 \\
& Online & 19 & 17 & 65 \\
\hline
\end{tabular}

However, we need to be cautious in interpreting the results since the sample size for the online courses is too small compared to the face-to-face classes. In this preliminary study students seem to believe that for the most part the quality of online and face-to-face courses is different. This is a research in progress and more data analyses are needed to find out more detailed information about the quality of the two delivery systems.

\section{CONCLUSION AND SUGGESTIONS}

There are several research implications for this study. However, it should be emphasized that more data is needed for online courses. In our study the data and the sample size for online courses were too small compared to the faceto-face classes.

An important finding in our study is that contrary to the beliefs of some in the research community, there is a significant difference in the quality of online and traditional (face-to-face) learning environment in students' perceptions. Therefore, our study results agree with those researchers who concluded that online and face-to-face courses do not have the same quality of learning. In light of these findings, perhaps those in the research community who believe that there's no difference in learning quality of the two learning modes need to reconsider their conclusions and search for more evidence. In addition, higher education institutions need to make an effort to support learning practices by providing more resources to improve the online environment.

The rapid growth of online learning calls for more research studies to further understand students' perceptions and capture their expectations for online learning experience. Further, research is needed to examine the extent that 
online courses could/should be incorporated as part of a traditional program. Furthermore, it needs to be determined whether students outside the business fields (e.g., education or nursing) would concur with business student perceptions of online learning. In addition, the issue of whether there is a difference in gender perceptions regarding the learning quality needs to be examined. These are intriguing areas for future research endeavors that could help traditional and online higher education institutions to design better online courses and learning models.

\section{REFERENCES}

1. AACSB Member Schools are Increasing Online Program Offerings. April/May 2010. Available from: http://www.aacsb.edu/publications/enewsline/datadirect.asp. [accessed 04/16/2010].

2. Allen, I. \& Seaman, J. Growing by degrees: Online education in the United States. 2005. Available from: http://www.sloan-c.org/resources/growing by degrees.pdf. [accessed 02/24/2010].

3. Aggarwal, A. K. and Bento, R. Web-based education. In A. Aggarwal (Ed), Web-based Learning and teaching technologies: opportunities and challenges, pp. 2-160. Hershey, PA: Idea Group. 2000.

4. Barker, B. O. The internet can improve education. In H. Cothran (Ed.). The internet: opposing viewpoints, pp. 79-87. San Diego, CA: Greehaven. 2002.

5. Beard, I. A. and Harper, C. Students perceptions of online versus on campus instruction. Education, 122, pp. 658-663. 2002.

6. Benhunan-Fich, R. and Arbaugh, J.B. Separating the effect of knowledge construction and group collaboration in learning outcomes of web-based courses. Information \& Management, 43, pp. 778-793. 2006.

7. Brown, D. and Ellison, C. What is active learning? In S. Hatfield (Ed), The seven principles in action: Improving undergraduate education, pp. 39-54. Boston: Anker. 1995.

8. Carrell, l. J. and Menzel, K. E. Variations in learning, motivation, and perceived immediacy between live and distance education. Communication Education, 50(3), pp. 230-241. 2001.

9. Conrad, R. and Donaldson, J. A. Engaging the online learner: Activities and resources for creative instruction. San Francisco: Jossey-Bass. 2004.

10. Gunawardena, C. N. and Zittle, F. J. Social presence as a predictor of satisfaction within a computer-mediated conferencing environment. American Journal of Distance Education, 11(3), pp. 8-26. 1997.

11. Hiltz, S. R. and Turoff, M. What makes learning networks effective? Communications of the ACM, 45(4), pp. 56-59. 2002.

12. Klesius, J. P. Homan, S. and Thompson T. Distance education compared to traditional education: the students' view. International Journal of Instructional' Media, 24, pp. 207-222. 1997.

13. Kuh, G. D. What we're learning about student engagement from NSSE. Change, 35, pp. 24-31. 2003.

14. McFarland, D. and Hamilton, D. Factors affecting students performance and satisfaction: Online vs. traditional course delivery. Journal of Computer Information Systems, 46(2), pp. 25-33. 2005.

15. Palloff, R. and Pratt, K. Lessons from cyberspace classroom. San Francisco: Jossey-Bass. 2001.

16. Plotrowski, C. and Vodanovich, S. J. Are the reported barriers to Internet-based instruction warranted? A synthesis of recent research. Education, 121, pp. 48-53. 2000.

17. Reynolds, J. Indicators of educational effectiveness. In S. Hatfield (Ed). The seven principles in action: Improving undergraduate education, pp. 107-114. Boston: Anker. 1995.

18. Robinson, C. and Hullinger, H. New Benchmarks in Higher Education: Student Engagement in Online Learning. Journal of Education for Business. November/December, 2008.

19. Rovai, A. P. Sense of community, perceived cognitive learning, and persistence in asynchronous learning networks. Internet and Higher Education, 5, pp. 319-332. 2002.

20. Russell, T. No significant difference phenomenon. 2006.Available from: Http://www.nosignificantdifference.org [accessed 01/23/2010].

21. Pethokoukis, J. M. E-learn and earn: As dot coms mostly fade, online universities are proving that there's gold in them that screens. U.S. News and World Report, 132(22), p. 36. June 24, 2002. 


\section{Volume XII, No. 2, pp 287-292, 2011}

22. Ponzurick, T. France, K. and Logar, C. Delivering graduate marketing education: an analysis of face-to-face versus distance education. Journal of Marketing Education, 22, pp. 180-187. 2000.

23. Russell, T. (2006). No significant difference phenomenon. Http://www.nosignificantdifference.org, Accessed January 23, 2010.

24. Simonson, M. Entering the mainstream: Distance education and higher education. Quarterly Review of Distance Education, 6(1), VII. 2005.

25. Wagner, E. D. In search of a functional definition of interaction. American Journal of Distance Education, 8(2), pp. 6-26. 1994. 